\title{
Modelling antiviral treatment to prevent hepatitis $C$ infection among people who inject drugs in Victoria, Australia
}

\section{Margaret E Hellard PhD, FRACP, FAFPHM Head' ' and Head of Hepatitis Services ${ }^{2}$ \\ Rebecca Jenkinson BEng(Geol), MEpid, PhD, \\ Peter Higgs \\ BSW, MA, PhD \\ NHMRC Post Doctora Fellow \\ Mark A Stoové BaAppSci(Hons) GradDip(Ed), PhD, Head HIV/STI Research Group,' and Adjunct Research Fellow \\ Rachel Sacks-Davis BA BSc(Hons[Arts]) Research Assistant and $\mathrm{PhD}$ student ${ }^{4}$ \\ Judy Gold BBiomedSci(Hons), PhD Research Assistant, Centre for Population Health Burnet Institute \\ Matthew Hickman MSc, PhD, FFPH Professor of Public Health and Epidemiology \\ Peter Vickerman DPhil, BSc, Senior Lecturer \\ Natasha K Martin Economic Modeller, ${ }^{5}$ and} Honorary Research Fellow

1 Centre for Population Health, Burnet Institute Melbourne, VIC

2 Infectious Diseases, Alfred Hospital, Melbourne, VIC

3 The Kirby Institute Sydney, NSW.

4 Department of Epidemiology and Preventive Medicine School of Public Health, Monash University, Melbourne, VIC

5 School of Social and Community Medicine University of Bristol Bristol, UK

6 Department of Global Health and Development,

Faculty of Public Health and Policy London School

of Hygiene and Tropica

of Hygiene and Tropical

hellard@burnet.edu.au

MJA 2012; 196: 638-641 doi: 10.5694/miall.1098 n developed countries, people who inject drugs (PWID) are the group at highest risk of infection with hepatitis $\mathrm{C}$ virus (HCV). ${ }^{1}$ Throughout the 1990s, regulations restricting access to antiviral treatment for $\mathrm{HCV}$ by PWID existed in many Western countries, although they were not evidence based. ${ }^{2}$

In the early 2000s, in Australia and elsewhere, guidelines changed to allow treatment of people who are current injecting drug users ${ }^{3}-$ however, hepatitis $\mathrm{C}$ virus (HCV) notifications among PWID in Australia remain high, and few currently receive HCV treatment. Australia's annual Needle and Syringe Program Survey indicates that, between 2005 and 2009 , only $4.7 \%-9.1 \%$ of respondents who knew they had HCV reported treatment for $\mathrm{HCV}$ (with interferon alone or interferon plus ribavirin [including pegylated interferon]) and less than $2 \%$ were being treated when interviewed. ${ }^{4}$ Furthermore, although prescribing of drugs to treat HCV has increased, ${ }^{5}$ few people who currently inject drugs in Australia receive treatment outside research projects. ${ }^{6}$

$\mathrm{HCV}$ treatment reduces an individual's risk of developing chronic liver disease, cirrhosis and hepatocellular carcinoma and improves quality of life. ${ }^{7}$ Treating HCV in people who currently inject drugs also has a broader public health benefit. One study indicated HCV treatment among PWID could reduce HCV infection prevalence in the general community in Australia; ${ }^{8}$ and recent modelling by Martin and colleagues ${ }^{9}$ suggested that only a small proportion of people who currently inject drugs need to be treated to significantly reduce $\mathrm{HCV}$ infection prevalence among PWID over 20 years. ${ }^{9}$

We adapted Martin et al's model ${ }^{9,10}$ to estimate the impact of HCV treatment on prevalence among PWID living in Victoria, Australia.

Objectives: To develop a mathematical model to project the potential impact of hepatitis $\mathrm{C}$ virus ( $\mathrm{HCV}$ ) treatment on $\mathrm{HCV}$ infection prevalence among people who inject drugs (PWID).

Design and setting: An existing model of HCV transmission among PWID was parameterised using data from Victoria, Australia, including specific parameter estimates of the number of people who are currently active injecting drug users, average duration of injecting, chronic HCV infection prevalence among PWID, annual mortality, and annual HCV treatment rate. We also explored the impact of prevalence uncertainty, program scale-up, and new treatments.

Main outcome measure: Prevalence of chronic HCV infection among people who are currently active injecting drug users.

Results: With annual treatment rates of 13, 17, or 25 per 1000 PWID, the model predicts relative prevalence reductions of $20 \%, 30 \%$, and $50 \%$, respectively, within 30 years. If new treatments giving higher sustained viral response rates are available in 5 years, estimated impact is increased by $21 \%-23 \%$ at 15 years, and $17 \%-38 \%$ at 30 years, depending on treatment rates.

Conclusions: This model suggests that modest rates of current HCV treatment among PWID in Victoria, Australia could halve HCV infection prevalence among PWID in 30 years. This finding suggests that interventions aimed at increasing access to HCV treatment in community clinics will benefit individual PWID and reduce $\mathrm{HCV}$ infection prevalence.

\section{Methods}

\section{Mathematical model and assumptions}

A previously developed model of HCV transmission among PWID ${ }^{9,10}$ (fully described in the Appendix; online at mja.com.au) was parameterised using data from Victoria, Australia. It consists of differential equations that track change among PWID who are susceptible (never infected, or previously infected and underwent spontaneous or treatment-induced clearance); who have chronic HCV infection; who are currently receiving treatment; and who do not achieve a sustained viral response (SVR) after treatment (and cannot be retreated). Previous modelling indicated that the presence of immunity has a negligible effect on treatment impact, 9,10 hence this model assumes no immunity. People who begin to inject drugs enter the susceptible pool and leave (by dying or ceasing to inject) at fixed rates. Susceptible PWID become infected at a rate proportional to infection risk and the prevalence of $\mathrm{HCV}$ among
PWID. PWID enter treatment at a fixed rate ( $\Phi$ PWID with chronic HCV infection per 1000 PWID annually) unless the number infected is driven below $\Phi$, whereupon all PWID with chronic $\mathrm{HCV}$ infection are treated. The model does not explicitly model individual genotypes, but we weighted the average SVR rate and treatment duration to the genotype distribution in Victoria.

\section{Model parameters}

We assumed treatment with pegylated interferon alfa and ribavirin leads to a $45 \%$ SVR rate for genotype 1 and $80 \%$ for genotype 2 or $3 .{ }^{11} \mathrm{~A}$ systematic review estimated that $26 \%$ of people with acute HCV infection spontaneously clear the disease. ${ }^{12}$

The baseline model included the Victorian estimates: population of PWID, 25000 (based on the number of PWID enrolled in opioid substitution treatment in Victoria, and selfreported opioid substitution treatment uptake data from epidemiological studies); ${ }^{13,14}$ average duration of injecting, 14 years; $^{6}$ prevalence of chronic HCV infection among PWID (as determined by a positive polymerase 
1 Estimated reduction in chronic HCV infection prevalence among PWID over time through initiating antiviral treatment at different rates*

$\square 13$ per 1000 PWID treated annually $\square 17$ per 1000 PWID treated annually ¿ $^{60}[\square 25$ per 1000 PWID treated annually

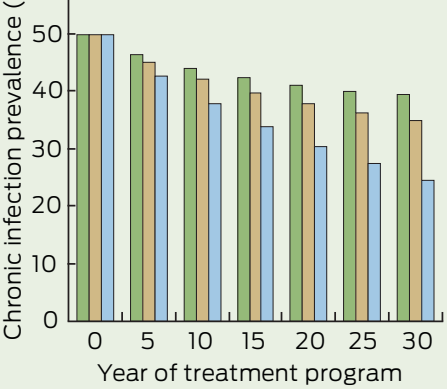

$\mathrm{HCV}=$ hepatitis $\mathrm{C}$ virus. $\mathrm{PWID}=$ people who inject drugs. * Baseline chronic prevalence, 50\%; baseline treatment rate, 1/1000 PWID annually.

chain reaction test result), $50 \% ; 4,15$ genotype 2 or $3,44 \%$, and genotype 1 , $56 \% ; 15,16$ mortality rate, $0.0083 \%$ per year; ${ }^{17}$ and annual HCV treatment rate, 1/1000 PWID. ${ }^{4}$ The Appendix (online at mja.com.au) contains a table of parameters.

\section{Baseline scenario}

We identified the treatment rates necessary to reduce HCV infection prevalence among PWID by $20 \%, 30 \%$, and $50 \%$ over 30 years, projecting the decrease in chronic infection prevalence at 5, 15, and 30 years. We determined the 15-year and 30-year relative prevalence reductions with annual treatment rates ranging from 5/1000 PWID to 40/1000 PWID.

\section{Alternative scenarios}

As estimates for baseline chronic infection prevalence among PWID in Victoria are uncertain, we explored the impact of lower (45\%) and higher (55\%) prevalences. Additionally, because of uncertainty in the average length of injecting and SVR rates among PWID, we examined scenarios with longer (16 years) and shorter (12 years) injecting durations (Appendix; online at mja.com.au).

As a substantial increase in treatment rates would require a gradual scale-up, we also explored a scenario where treatment increased linearly from baseline to the full treatment rate over 5 years. In this model, we explored the potential impact of new, direct-acting antiviral therapies with improved efficacy and shorter treatment duration. We modelled scenarios with an $80 \%$ SVR rate and a 24 -week treatment duration for all genotypes after year 5 .

Finally, we examined a scenario where uptake increased because of new treatments with higher SVR rates and shorter duration. We compared treating 5/1000 PWID annually with baseline SVR rates to the following scenario: 5/1000 treated for 5 years with baseline SVR and treatment duration rates, followed by 20 / 1000 treated for the remaining years with an $80 \%$ SVR rate and 24 weeks of treatment.

\section{Results}

Our model predicted that reducing chronic HCV infection prevalence by $50 \%$ among PWID within 30 years (from $50 \%$ to $25 \%$ ) could be achieved with an annual treatment rate of 625 PWID in Victoria (25/1000 PWID), including reductions in prevalence of $14 \%$ by 5 years and $32 \%$ by 15 years (Box 1). We also estimated the effect of treating 13/1000 and 17/1000 PWID annually (Box 1).

Box 2 shows the estimated relative reductions in prevalence at 15 and 30 years with varying annual treatment rates. Increasing annual treatment rates resulted in greater prevalence reductions at 30 years compared with 15 years, but above a rate of 30/1000 PWID the incremental impact plateaued (maximum relative prevalence reduction, approximately $70 \%$ ) because many PWID become persistent non-responders with currently available treatments (Appendix; online at mja.com.au).

The reduced HCV infection prevalence among PWID remained when baseline HCV prevalence (Box 3) and average duration of injecting (Appendix; online at mja.com.au) varied, although higher baseline prevalences and shorter duration of injecting showed a reduced impact.

Introducing a 5-year scale-up period before reaching full treatment rates reduced the impact of treatment by $10 \%-14 \%$ at 15 years (Box $4, A$ ), but the differences were minimal at 30 years (Box $4, B)$. If new treatments increased SVR to $80 \%$ and decreased treatment duration to 24 weeks for both genotypes after 5 years, the
2 Estimated effect of treatment rate* on relative reduction in chronic $\mathrm{HCV}$ infection prevalence ${ }^{\dagger}$ among PWID at 15 and 30 years

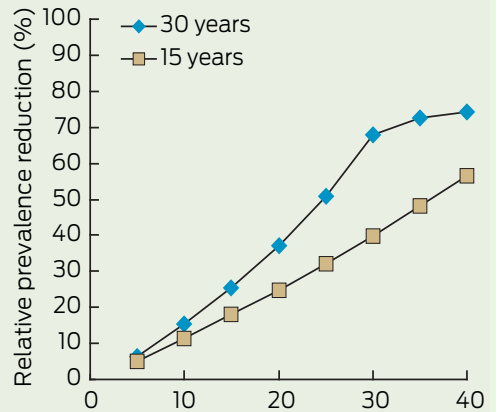

Treatments initiated per 1000 PWID annually

$\mathrm{HCV}=$ hepatitis $\mathrm{C}$ virus. $\mathrm{PWID}=$ people who nject drugs. * Assuming immediate scale-up to full treatment rate. $†$ Baseline chronic prevalence, 50\%; baseline treatment rate, 1 per 1000 PWID annually.

estimated impact would increase by $20 \%-26 \%$ at 15 years, and $17 \%-38 \%$ by 30 years, depending on the scaleup strategy.

A benefit was predicted from new treatments resulting in higher SVR with shorter treatment durations when uptake was increased from 5/ 1000 to 20/1000 after 5 years (Box 5); the projected HCV infection prevalence was nearly half the baseline prevalence by 30 years. Maintaining the treatment rate at 5/1000 showed minimal impact (prevalence of $47 \%$ at 5 years and $46 \%$ at 30 years).

\section{Discussion}

Our modelling suggests that modest rates of $\mathrm{HCV}$ treatment among people who currently inject drugs could halve $\mathrm{HCV}$ infection prevalence among PWID in 30 years in Victoria. Although this is particularly relevant to Victoria, as the Victorian Government has recently funded ten $\mathrm{HCV}$ treatment nurses to work in community-based clinics in urban and regional Victoria, similar impacts on $\mathrm{HCV}$ infection prevalence are possible elsewhere in Australia. Our findings suggest that structuring clinics and nurses' roles to improve timely access to $\mathrm{HCV}$ treatment and to support adherence and treatment completion for PWID could produce considerable population-level reductions in $\mathrm{HCV}$ transmission. Moreover, new $\mathrm{HCV}$ treatment therapies are likely to become available soon, including 
3 Estimated impact of uncertainty in baseline chronic HCV infection prevalence on relative prevalence reduction among PWID at 30 years, by treatment rate*

$\neg-55 \%$ chronic prevalence

- 45\% chronic prevalence

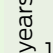

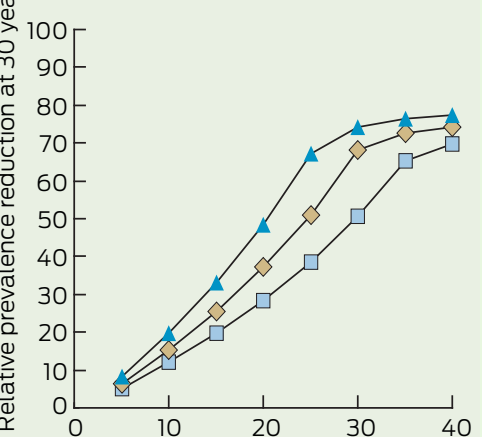

Treatments initiated per 1000 PWID annually

$\mathrm{HCV}=$ hepatitis $\mathrm{C}$ virus. $\mathrm{PWID}=$ people who inject drugs. * Baseline treatment rate, 1 per 1000 PWID annually.

regimens that are not based on pegylated interferon. ${ }^{18,19}$ Treatment outcomes (SVR rates) will improve for all patients, irrespective of viral genotype and their previous response to therapy. Treatment length will decrease, as will drug side effects, ${ }^{20,21}$ further increasing the projected impact of treatment on HCV infection prevalence. $^{20}$

In the past, concerns about treating PWID have included lack of compliance with therapy, associated drug resistance, and the potential for
○ $\prec 50 \%$ chronic prevalence (baseline)

reinfection. ${ }^{22}$ These concerns may discourage clinicians from recommending HCV treatment and deter health service bureaucrats from funding clinics that are appropriately located and structured to meet the complex health needs of PWID. A recent Australian study of HCV treatment uptake and deferral, using data from the Australian Chronic Hepatitis C Observational Study, identified factors related to drug and alcohol use rather than clinical factors as the major influences on treatment uptake. ${ }^{23}$ A recent systematic review of HCV treatment for PWID found adequate levels of adherence in this population and low levels of reinfection after successful treatment; ${ }^{24}$ and a subsequent study of treatment of acute and early chronic hepatitis reported high levels of adherence regardless of reported injecting behaviour. ${ }^{25}$ Internationally, several studies in a range of settings have demonstated that successful treatment of current injectors is possible; ${ }^{6,26}$ one study reports high treatment adherence, irrespective of injecting drug use before or during therapy. 6,25 Additionally, the rate of reinfection after treatment has been shown to be low. ${ }^{27}$

Knowledge about HCV diagnosis and management in the primary care setting in Australia is poor, ${ }^{28}$ and considerable work is needed to ensure primary care clinics can appropriately

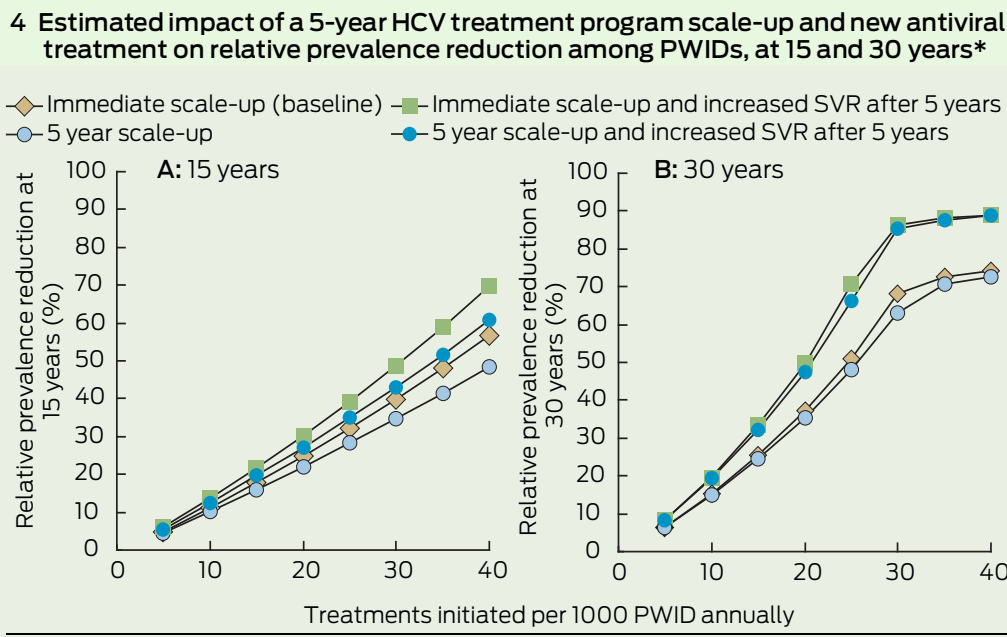

HCV $=$ hepatitis $C$ virus. PWID = people who inject drugs. SVR = sustained viral response. $*$ Baseline treatment rate, 1 per 1000 PWID annually. Results are shown for immediate scale-up from baseline to full treatment rate (baseline scenario); 5 -year scale-up to full treatment rate; immediate scale-up but with an increased SVR ( $80 \%$ ) and decreased treatment duration ( 24 weeks) after 5 years (to but with an increased SVR ( $80 \%)$ and decreased treatment duration (24 weeks) after 5 years (to
reflect new direct-acting antiviral treatments); and 5-year scale-up with an increased SVR ( $80 \%)$ and decreased treatment duration ( 24 weeks) after 5 years.
5 Estimated impact on chronic $\mathrm{HCV}$ infection prevalence when treatment rates increase after 5 years due to higher uptake of new treatments*

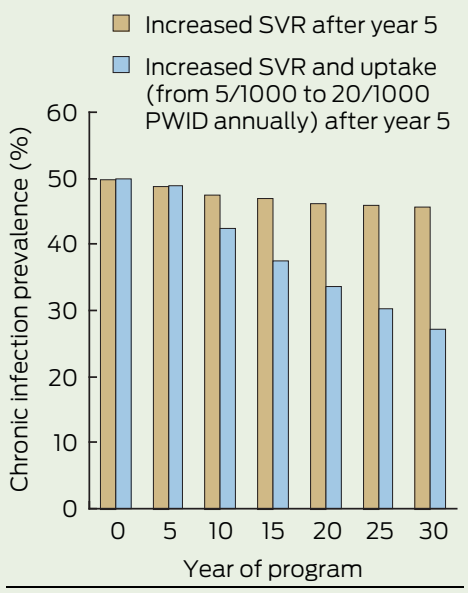

$\mathrm{HCV}=$ hepatitis $\mathrm{C}$ virus. PWID = people who inject drugs. SVR = sustained viral response. * In both scenarios, the SVR rate increased (to $80 \%$ ) and treatment duration decreased (to 24 weeks) after 5 years. Brown bars show the projected prevalence when 5 per 1000 PWID are treated annually. Blue bars show the prevalence expected when 5 per 1000 PWID are treated for 5 years, and 20 per 1000 PWID treated thereafter.

manage $\mathrm{HCV}$ infection in PWID. However, Australian primary health care practitioners have considerable experience in managing complex chronic diseases affecting patients with multiple and complex health needs - for example, diabetes, HIV and problems with mental health. ${ }^{29}$ With appropriate training and adequate resourcing it should be feasible for them to manage HCV infection in PWID, particularly if systems are developed to facilitate shared-care and timely referral of complex patients to HCV specialists. ${ }^{30}$

The model's prediction that treating people who currently inject drugs will reduce prevalence and $\mathrm{HCV}$ transmission despite risk of reinfection suggests that it is worthwhile funding the treatment of $\mathrm{HCV}$ infection in PWID, even if managing this group is resource-intensive. ${ }^{31}$ Such a policy would involve locating $\mathrm{HCV}$ nurses in primary care services attended by a high proportion of PWID and ensuring that other support services are available, including mental health, drug and alcohol, social welfare, housing and peer support.

Our study has limitations. While estimates for the model parameters 
were generated from multiple data sources, injecting drug use is a highly stigmatised and typically hidden behaviour, so the number of PWID in Victoria and mean duration of injecting are uncertain. Our findings are based on a predictive model rather than experimental evidence or observations in other communities, and assumes that, after scale-up, treatment rates will be constant for 30 years (for example, 625 PWID treated annually); however, as HCV infection prevalence decreases, so may demand for $\mathrm{HCV}$ treatment. Conversely, increasing awareness and improvement of treatment may lead to increased treatment uptake. We assumed that the rate of initiation to injecting remains constant over time. The population of PWID may increase due to general population growth or decrease due to changing drug-use patterns, although numbers in Victoria have been stable over the past 15 years. $^{32}$

Finally, the model assumes that risky injecting behaviours and $\mathrm{HCV}$ infection prevalence are homogenously distributed among PWID and that all infected PWID have equal probability of HCV acquisition, treatment access, and treatment success. Assuming population heterogeneity in HCV risk and treatment accessibility may lead to the model overestimating the impact of treating 625 PWID annually.

PWID are at greatest risk of acquiring and transmitting $\mathrm{HCV}$ infection, but very few are being treated. Because of the high risk of onward transmission, even modest increases in treatment rates in this group may lead to considerable population-level reductions in $\mathrm{HCV}$ infection prevalence. Particularly when considered in combination with the value of treatment to individuals, this finding suggests there are real benefits in investing additional resources in treating PWID.

Acknowledgements: We thank Soenke Tremper (General Practice Victoria), Joe Sasadeusz (Royal Melbourne and Alfred Hospitals), Jacqui Richmond (St Vincent's Hospital), Kate Mellor (St Vincent's Hospital), Sally von Bibra (Alfred Hospital), Anna Wilkinson (Alfred Hospital) for expert input that informed our parameter estimates.

Margaret Hellard was supported by a National Health and Medical Research Council (NHMRC) Research Fellowship. Rachel Sacks-Davis was supported by an NHMRC PhD scholarship. Peter Higgs was supported by an NHMRC Research Post Doctoral Fellowship. Natasha Martin was supported by Health Protection Scotland. Peter Vickerman was supported by the Medical Research Council, UK. Rebecca Jenkinson and Mark Stoové were supported by Centre for Research Excellence into Injecting Drug Use Fellowships.

Competing interests: No relevant disclosures

Received 31 Jul 2011, accepted 24 Jan 2012.

1 Aceijas C, Rhodes T. Global estimates of prevalence of HCV infection among injecting drug users. Int J Drug Policy 2007; 18: 352-358.

2 Edlin BR. Hepatitis C prevention and treatment for substance users in the United States: acknowledging the elephant in the living room. Int J Drug Policy 2004; 15: 81-91.

3 Australian Government Department of Health and Aged Care. Schedule of Pharmaceutical Benefits for Approved Pharmacists and Medical Practitioners. Canberra: Department of Health and Aged Care and Medicare Australia Pharmaceutical Benefits Scheme, 2001.

4 National Centre in HIV Epidemiology and Clinical Research. Australian NSP Survey National Data Report 2005-2009. Sydney: National Centre in HIV Epidemiology and Clinical Research, University of New South Wales, 2010. http:// www.med.unsw.edu.au/NCHECRweb.nsf/ resources/NSP Complete2/\$file/ ANSP.NDR.2005_2009.pdf (accessed Feb 2012).

5 Gidding HF, Topp L, Middleton M, et al. The epidemiology of hepatitis C in Australia: notifications, treatment uptake and live transplantations, 1997-2006. J Gastroenterol Hepatol 2009; 24: 1648-1654.

6 Dore GJ, Hellard M, Matthews GV, et al. Effective treatment of injecting drug users with recently acquired hepatitis $C$ virus infection. Gastroenterology 2010; 138: 123-135.el-2.

7 Shepard CW, Finelli L, Alter MJ.Global epidemiology of hepatitis C virus infection. Lancet Infect Dis 2005; 5: 558-567.

8 Zeiler I, Langlands T, Murray JM, Ritter A. Optimal targeting of Hepatitis C virus treatment among injecting drug users to those not enrolled in methadone maintenance programs. Drug Alcohol Depend 2010; 110: 228-233.

9 Martin N, Vickerman P, Foster G, et al. Can antiviral therapy for Hepatitis C reduce the prevalence of HCV among injecting drug user populations? A modeling analysis of its prevention utility. J Hepatol 2011; 54: 1137-1144.

10 Martin NK, Vickerman P, Hickman M. Mathematical modelling of hepatitis C treatment for injecting drug users. J Theor Biol 2011; 274: 58-66.

11 National Institute for Clinical Excellence. Interferon alfa (pegylated and non-pegylated) and ribavirin for the treatment of chronic hepatitis C: Technology Appraisal Guidance 75 January 2004. London: NICE, 2004. http:// www.nice.org.uk/nicemedia/live/11524/32809/ 32809.pdf (accessed Feb 2012).

12 Micallef JM, Kaldor JM, Dore GJ. Spontaneous viral clearance following acute hepatitis C infection: a systematic review of longitudinal studies.J Viral Hepat 2006; 13: 34-41.

13 Horyniak D, Franklin L, Aitken C, et al. Recruiting injecting drugs users using respondent driven sampling (RDS): experiences from the Melbourne injecting drug user cohort study (MIX). Drug Alcohol Rev 2009; 28 Suppl 1: A30.

14 Reddel SE, Horyniak D, Dietze D, McElwee P. Victorian Drug Trends 2010: findings from the Illicit Drug Reporting System (IDRS). Australian Drug Trends Series No. 58. Sydney: National Drug and Alcohol Research Centre, University of New South Wales, 2011. http:// ndarc.med.unsw.edu.au/resource/victoriandrug-trends-2010-findings-illicit-drug-reportingsystem-idrs (accessed Feb 2012).
15 Aitken CK, Lewis J, Tracy SL, et al. High incidence of hepatitis $C$ virus reinfection in a cohort of injecting drug users. Hepatology 2008; 48: 17461752.

16 McCaw R, Moaven L, Locarnini SA, Bowden DS. Hepatitis C virus genotypes in Australia. J Viral Hepat 1997; 4: 351-357.

17 Stoové MA, Dietze PM, Aitken CK, Jolley D. Mortality among injecting drug users in Melbourne: a 16-year follow-up of the Victorian Injecting Cohort Study (VICS). Drug Alcohol Depend 2008; 96: 281-285.

18 Gane EJ, Stedman CA, Hyland RH, et al. Oncedaily PSI-7977 plus RBV: pegylated interferonalfa not required for complete rapid viral response in treatment-naïve patients with $\mathrm{HCV}$ GT2 or GT3 [abstract]. The Liver Meeting 2011. 62 nd Annual Meeting of the American Association for the Study of Liver Diseases; 2011 Nov 4-8; San Francisco, CA. Hepatology 2011; 54 Suppl 1: 377A.

19 Zeuzem S, Asselah T, Angus PW, et al. High sustained virologic response following interferonfree treatment of chronic HCV GTl infection for 4 weeks with HCV protease inhibitor BI201335, polymerase inhibitor BI207127 and ribavirin, followed by BI201335 and PegIFN/ribavirin - the SOUND-Cl study [abstract]. Hepatology 2011; 54 Suppl 1: 249A.

20 McHutchison JG, Manns MP, Muir AJ, et al; PROVE3 Study Team. Telaprevir for previously treated chronic HCV infection. N Engl J Med 2010; 362: 1292-1303.

21 Welsch C, Zeuzem S. Will interferon-free regimens prevail? Gastroenterology 2012; 142: $1351-1355$.

22 Foster GR. Injecting drug users with chronic hepatitis C: should they be offered antiviral therapy? Addiction 2008; 103: 1412-1413.

23 Gidding HF, Law MG, Amin J, et al. Predictors of deferral of treatment for hepatitis C infection in Australian clinics. Med J Aust 2011; 194: 398-402.

24 Hellard M, Sacks-Davis R, Gold J. Hepatitis C treatment for injection drug users: a review of the available evidence. Clin Infect Dis 2009; 49: 561-573.

25 Grebely J, Matthews G, Hellard M, et al. Adherence to treatment for recently acquired hepatitis C virus (HCV) infection among injecting drug users. J Hepatol 2011; 55: 76-85.

26 Belfiori B, Ciliegi P, Chiodera A, et al. Peginterferon plus Ribavirin for chronic hepatitis C in opiate addicts on methadone/buprenorphine maintenance therapy. Dig Liver Dis 2009; 41 : 303-307.

27 Backmund M, Meyer K, Edlin BR. Infrequent reinfection after successful treatment for hepatitis $C$ virus infection in injection drug users. Clin Infect Dis 2004: 39: 1540-1543.

28 Hellard ME, Wang YH. The role of general practitioners in managing and treating hepatitis C [editorial]. Med J Aust 2009; 191: 523-524.

29 Dennis SM, Zwar N, Griffiths R, et al Chronic disease management in primary care: from evidence to policy. Med J Aust 2008; 188 (8 Suppl): S53-S56.

30 Harris MF, Williams AM, Dennis SM, et al. Chronic disease self-management: implementation with and within Australian general practice. Med J Aust 2008; 189 (10 Suppl): S17-S20.

31 Norman J, Walsh NM, Mugavin J, et al. The acceptability and feasibility of peer worker support role in community based HCV treatment for injecting drug users. Harm Reduct J 2008; 5: 8.

32 Australian Institute of Health and Welfare. 2010 National Drug Strategy Household Survey report. Canberra: AlHW, 2011. (AlHW Cat. No. PHE 145; Drug Statistics Series No. 25.) http:// www.aihw.gov.au/publication-detail/?id= 32212254712 (accessed Feb 2012). 